\title{
Evaluation of the Current Knowledge About Bacterial Endocarditis Prevention Among General Dentists in the City of Santo Domingo, Dominican Republic
}

\author{
Juan Manuel Aragoneses ${ }^{1}$, Javier Aragoneses ${ }^{2}$, Vanessa Arlette Brugal ${ }^{3}$, Juan Algar ${ }^{4}$ and \\ Ana Suarez ${ }^{5 *}$ \\ ${ }^{1}$ Department of Dental Research, Federico Henriquez y Carvajal University, Santo Domingo, Dominican Republic, \\ ${ }^{2}$ Department of Dentistry, Federico Henriquez y Carvajal University, Santo Domingo, Dominican Republic, ${ }^{3}$ Department of \\ Pediatric Dentistry and Orthopedics, School of Dentistry, Universidad Autónoma de Santo Domingo, Santo Domingo, \\ Dominican Republic, ${ }^{4}$ Department of Clinical Dentistry, School of Biomedical Sciences, Universidad Europea de Madrid, \\ Madrid, Spain, ${ }^{5}$ Department of Preclinical Dentistry, School of Biomedical Sciences, Universidad Europea de Madrid, \\ Madrid, Spain
}

OPEN ACCESS

Edited by:

Allen C. Meadors,

Independent Researcher, West End

NC, United States

Reviewed by:

Nili Tickotsky-Moskovitz, Bar-Ilan University, Israel

Natalio Garcia-Honduvilla,

University of Alcala, Spain

*Correspondence:

Ana Suarez

ana.suarez@universidadeuropea.es

Specialty section:

This article was submitted to

Public Health Education and

Promotion,

a section of the journal

Frontiers in Public Health

Received: 20 July 2020 Accepted: 30 October 2020 Published: 24 November 2020

Citation:

Aragoneses JM, Aragoneses $\mathrm{J}$ Brugal VA, Algar J and Suarez A (2020) Evaluation of the Current

Knowledge About Bacterial

Endocarditis Prevention Among

General Dentists in the City of Santo Domingo, Dominican Republic.

Front. Public Health 8:585332.

doi: 10.3389/fpubh.2020.585332
Infective endocarditis (IE) is a life-threatening disease caused by bacterial adherence to the lining of the heart and heart valve, and it can be caused by bacterial contamination of the bloodstream during invasive dental procedures. The American Heart Association (AHA) recommended guidelines for antibiotic prophylaxis in 2008 before invasive dental procedures; however, in the Dominican Republic, no official guidelines or regulations on this topic have been yet established. This study aimed to evaluate the current knowledge about bacterial endocarditis prevention among dentists in Santo Domingo. The study participants were dentists who attended a conference organized by Universidad Federico Henríquez y Carvajal ( $n=95)$, of which 74 responded to the questionnaire survey. Seventy-eight percentage of the participants responded that an indication of antibiotics is recommended in cases of prophylaxis for IE. The prescription of antibiotics was applied to patients with prosthetic valves (78.4\%), presented a history of previous IE (77\%) among others. Among all the interventions in which the respondents would prescribe antibiotics, tooth extraction (70.7\%) was the most frequent. Amoxicillin was the preferred drug choice $(63.5 \%)$ and clindamycin was the antibiotic of choice in allergic patients (55.4\%). Even though the choice of antibiotics were according to AHA guidelines (2008), majority of the dentists (58.82 and 55.4\%) were not aware of the correct dosage and timing of administration of azithromycin and clindamycin in drugs in patients allergic to penicillin.

Keywords: bacterial endocarditis, preoperative antibiotic prophylaxis, amoxicillin, antibiotics, Dominican Republic

\section{INTRODUCTION}

Infective endocarditis (IE) is a life-threatening disease that is caused by bacterial adherence to the lining of the heart and the valves of the heart (1). The morbidity and mortality rates in the affected patients can be as high as $80 \%$ (2). The survival of the patients with repeated infections of this disease has been reduced to $60 \%$ (3). A 10 -year review of cases reported that 
the incidence of this disease was 0.36 cases per million population and there was about $16 \%$ median in-hospital mortality. The disease is either acquired, congenital, or due to cardiac defects, however, it has also been shown to occur during dental procedures where the existing data is still controversial (1, 4, 5). During tissue injury, a variety of microorganisms present in the oral cavity can enter into the bloodstream. Invasive dental procedures like root canal treatment, extractions, and periodontal procedures can result in increased infections in the heart, especially in patients already suffering from heart disease (2). Hence, some authors recommend antibiotic prophylaxis for patients suffering from a heart condition that may catalyze in IE $(1,2)$.

The most commonly used guidelines for antibiotic prophylaxis have been proposed by the American Heart Association (AHA) in 2008 and that has been approved by American Dental Association (ADA) and endorsed by the Canadian Dental Association $(2,6)$. The guidelines state that antibiotic prophylaxis is required in dental procedures where there is a manipulation of gingival tissues, periapical region, or perforation of oral mucosa that has been performed in patients with specified cardiac conditions (ex: prior episode of IE, prosthetic valve) (2). According to the guidelines, the recommended antibiotic regimen is Amoxicillin for adults $(2 \mathrm{~g})$ and children $(50 \mathrm{mg} / \mathrm{kg})$, at least $30 \mathrm{~min}$ before the start of the dental procedure. If adults were unable to consume oral medication, $2 \mathrm{~g}$ Ampicillin, or $1 \mathrm{~g}$ Cefazolin or Ceftriaxone by intramuscular (IM) or intravenous (IV) administration has been recommended. Drugs like Azithromycin or Clarithromycin have been suggested in patients who were allergic to penicillin (2).

There was a stark contrast to the guidelines published by the National Institute for Health and Clinical Excellence (NICE) in 2008 (7). It stated that patients undergoing interventional procedures that involve the dental, upper and lower respiratory tract, genitourinary tract, or upper and lower gastrointestinal tract need not be offered antibiotic prophylaxis against infective endocarditis and patients with pre-existing cardiac conditions should be considered as high-risk (7). But, a study conducted by Dayer et al., between the years 2000 and 2013 showed that there was a higher incidence of cases with IE following the publication of NICE guidelines (8). However, the recommendations have been upheld by NICE during its review in 2015 and it had added that chlorhexidine mouthwash cannot be given to patients as a mode of prophylaxis for patients prone to IE (9). In 2016, the institute amended its recommendation stating that when the individuals were considered to be at high risk for IE or when patients preferentially expressed the need for antibiotic prophylaxis, then the prophylactic regimen may be appropriate in such cases (10).

Despite the many modifications in guidelines proposed by various organizations, there is still a dearth of evidence regarding the effectiveness of antibiotic prophylaxis against infective endocarditis $(11,12)$. There has been a cloud of controversy regarding the NICE guidelines and this may be because all these recommendations were based on observational cohort studies rather than randomized controlled clinical trials (11, 13, 14). In the US, a study conducted by Lockhart et al., showed that there was a high acceptance of 2007 (>75\%) AHA guidelines when a survey was conducted among 901 dentists in routine clinical practice (15). Another study conducted by Elad et al., in 2010 observed that the acceptance of AHA guidelines remained moderate to high among patients in Israel (16). The knowledge and acceptance of these guidelines were found to be significantly high among Israeli dentists (17). But, there has been a paucity of evidence regarding the knowledge and awareness of pre-operative antibiotic prophylaxis among dentists in the Dominican Republic. With due consideration to the lack of guidelines proposed by any official organization in the country, the aim of this cross-sectional study was to evaluate the current knowledge and awareness about the prevention of IE among dentists in the city of Santo Domingo.

\section{MATERIALS AND METHODS}

The research protocol was approved by Universidad Federico Henríquez y Carvajal, Ethics Committee (2/04/2017) and it followed the Helsinki declaration. A survey was carried out among dentists $(n=95)$ who attended a conference organized by Universidad Federico Henríquez y Carvajal in 2017 for improvement in teaching methodologies. The conference was attended by Professors from the University and many dentists from the city of Santo Domingo. After reading the summary of the study protocol, and informed consent was obtained from the study participants who were willing to participate. The attendants who refused to participate or provided incomplete surveys were excluded from the study. The questionnaire was delivered and collected by one of the researchers in this study.

\section{Questionnaire}

The questionnaire comprised two sections (Appendix) where the initial three questions probed the demographic information about the dentists such as age, sex, and professional experience (in years). There were two questions on the knowledge regarding antibiotic prophylaxis depending on the source i.e., either by classroom teaching in the undergraduate degree or by reading research articles among dentists and the score was assessed based on a scale from 1 to 10 . The remainder of the questions focused on the knowledge and awareness among dentists about IE, the cardiac conditions warranting antibiotic prophylaxis, the dental procedures that require prophylaxis, and the commonly used antibiotics for the prophylactic regimen. It also assessed the dentists' awareness of drug usage in allergic and non-allergic patients. The question on the awareness of cardiac conditions that require prophylaxis according to AHA guidelines consisted of the following 16 conditions: congenital heart disease, prosthetic valve, previous history of IE, stent, ischemic heart disease, atrial septal defects, ventricular septal defect, rheumatic heart disease, untreated cyanotic heart disease, heart bypass surgery, pacemaker insertion, mitral valve prolapse or regurgitation, physiological heart murmur, history of cardiac surgery, heart transplant, and heart transplant patients with valvular disease.

The awareness among dentists on the dental procedures that warrant antibiotic prophylaxis was assessed by proposing 
TABLE 1 | Demographic characteristics of the study population.

\begin{tabular}{lcc}
\hline Variables & Frequency & Percentages \\
\hline Age (years) & 11 & \\
$25-34$ & 28 & 14.86 \\
$35-44$ & 28 & 37.84 \\
$45-54$ & 7 & 37.84 \\
$55-64$ & & 9.46 \\
Sex & 27 & \\
Male & 47 & 36.49 \\
Female & & 63.51 \\
Professional experience (years) & 16 & \\
0-11 & 40 & 21.62 \\
12-22 & 18 & 54.05 \\
$23-33$ & & 24.32 \\
\hline
\end{tabular}

a multitude of different procedures $(n=25)$ from various specialties in dentistry: Infiltrative local anesthesia, inferior alveolar nerve block, intraligamentary anesthesia, tooth extraction, replantation of teeth, incision and drainage of the abscess, scaling using an ultrasonic scaler, periodontal probing, scaling and root planning, periodontal surgery, dental implant surgery, bone grafting, sinus lift, suture removal, Implant surgery (second stage), biopsy, endodontic therapy, apicoectomy, dental isolation using clamps, dental impression, orthodontic band placement, gingival retraction using cords, tooth carving that includes gingival bleeding, matrix band, and wedge placement, and removal of subgingival caries. The last section of the questionnaire focused on the type of antibiotic drug, timing, and dosage to be used in allergic and non-allergic patients for the prevention of IE.

\section{Statistical Analysis}

The data were entered into Microsoft Excel workbook and exported into SPSS v21.0 (IBM, SPSS Inc, Chicago Ill., USA). The data has been expressed as frequency, percentages, median, and interquartile range. Skewed data were compared using Mann Whitney $U$-test. A $p$-value of less than 0.05 was considered statistically significant.

\section{RESULTS}

\section{General Characteristics}

Among 95 dentists who attended the conference, only 74 participants were included in the questionnaire study. The demographic characteristics of the study population have been depicted in Table 1. About $37.84 \%$ of the participants were between 35-44 and 45-54 years' age group and when combined, they made up $75 \%$ of the study population. The gender ratio (male: female) in the study population was $0.57: 1$, with considerably more female dentists, participated in the study. More than half of the study population (54\%) had professional clinical experience between 12 and 22 years.
TABLE 2 | Assessment of awareness among dentists regarding the indication (cardiac condition) of antibiotic prophylaxis for prevention of IE.

\begin{tabular}{lcc}
\hline Cardiac conditions & Frequency & Percentages \\
\hline Prosthetic valve & 58 & 78.4 \\
Previous infectious endocarditis & 57 & 77.0 \\
Rheumatic heart disease & 55 & 74.3 \\
Congenital heart disease & 50 & 67.6 \\
Atrial septal defects & 47 & 63.5 \\
Heart transplant patients with heart valve disease & 47 & 63.5 \\
Ventricular septal defect & 45 & 60.8 \\
Untreated cyanotic heart disease & 43 & 58.1 \\
Stent & 43 & 58.1 \\
Ischemic heart disease & 37 & 50.0 \\
History of cardiac surgery & 36 & 48.6 \\
Heart bypass surgery & 30 & 40.5 \\
Heart transplant & 25 & 33.8 \\
Mitral valve prolapse or regurgitation & 17 & 23.0 \\
Pacemaker insertion & 9 & 12.2 \\
Physiological heart murmur & 4 & 5.4 \\
\hline
\end{tabular}

\section{Knowledge Score}

The median knowledge score acquired during classroom study was significantly lower than the score obtained through reading research articles $[7.0(6.0,8.0)$ vs. $8.0(7.0,9.0)]$ and it showed very high statistical significance with $p<0.0001$.

\section{Indication for Antibiotic Prophylaxis for IE}

The dentists were questioned on the cardiac conditions that indicate antibiotic prophylaxis based on the current guidelines. The majority of the participants $(78.4 \%)$ mentioned prosthetic valve, followed by the previous infection of IE (77\%), rheumatic heart disease $(74.3 \%)$, congenital heart disease $(67.6 \%)$, and atrial septal defects $(63.5 \%)$. The least percentage of responses were for conditions like physiological heart murmur (5.4\%), pacemaker insertion (12.2\%), and mitral valve prolapse or regurgitation (23\%) (Table 2).

\section{Dental Procedures for Prescribing Antibiotics for the Prevention of IE}

The majority of the respondents stated dental procedures like tooth extraction $(70.7 \%)$, abscess drainage $(70.7 \%)$, inferior alveolar nerve block (68.9\%), tooth replantation $(68.9 \%)$, bone grafting $(62.2 \%)$, and dental implant surgery with or without sinus lift $(60.8 \%)$ require an antibiotic prescription for prevention of IE. The dental procedures that received the least positive response were for matrix band and wedge placement $(5.4 \%)$, gingival retraction using cords (6.8\%), a dental impression (6.8\%), and subgingival caries removal (8.1\%) (Table 3).

\section{Choice of Antibiotics for IE}

Amoxicillin was the most preferred antibiotic among dentists with over $63.5 \%$ of the study population warranting its usage for the prevention of IE in non-allergic patients when performing dental procedures. It was followed by amoxicillin+clavulanic 
TABLE 3 | Assessment of awareness among dentists for different dental procedures that indicate antibiotic prophylaxis to prevent IE.

\begin{tabular}{|c|c|c|}
\hline Dental procedures & Frequency & Percentages \\
\hline Tooth extraction & 52 & 70.7 \\
\hline Incision to drain an abscess & 52 & 70.7 \\
\hline Inferior alveolar nerve block & 51 & 68.9 \\
\hline Replantation of teeth & 51 & 68.9 \\
\hline Bone grafting & 46 & 62.2 \\
\hline Dental implant surgery & 45 & 60.8 \\
\hline Sinus lift & 45 & 60.8 \\
\hline Apicoectomy & 44 & 59.5 \\
\hline Scaling and root planing & 42 & 56.8 \\
\hline Periodontal surgery & 42 & 56.8 \\
\hline 2nd implant surgery & 42 & 56.8 \\
\hline Biopsy & 42 & 56.8 \\
\hline Dental cleanings using ultrasonic scalers & 36 & 48.6 \\
\hline tooth carving that include gingival bleeding & 36 & 48.6 \\
\hline Periodontal probing & 31 & 41.9 \\
\hline Infiltrative local anesthesia & 28 & 37.8 \\
\hline Intraligamentary anesthesia & 28 & 37.8 \\
\hline Endodontics therapy & 24 & 32.4 \\
\hline Suture removal & 21 & 28.4 \\
\hline Dental isolation clamps placement & 20 & 27.0 \\
\hline Orthodontic bands placement & 10 & 13.5 \\
\hline Removal of subgingival caries & 6 & 8.1 \\
\hline Dental impression & 5 & 6.8 \\
\hline gingival retraction with retraction cords & 5 & 6.8 \\
\hline Matrix band and wedges placement & 4 & 5.4 \\
\hline
\end{tabular}

TABLE 4 | Choice of antibiotics in non-allergic patients for the prevention of IE among the dentists.

\begin{tabular}{lcc}
\hline Antibiotic drug & Frequency & Percentages \\
\hline Amoxicillin & 47 & 63.5 \\
Azithromycin & 1 & 1.35 \\
Clindamycin & 2 & 2.70 \\
Amoxicillin + clavulanic acid & 4 & 5.40 \\
\hline
\end{tabular}

acid (5.4\%), clindamycin (2.7\%), and azithromycin (1.35\%) was the least preferred antibiotic among the dentists (Table 4). In allergic patients, the preferred antibiotic and dosage was azithromycin (500 mg, $2 \mathrm{~h}$ before the procedure) followed by clindamycin ( $300 \mathrm{mg}, 1$ day prior to procedure), and clindamycin (600 $\mathrm{mg}, 1 \mathrm{~h}$ before the procedure). The least likely antibiotic dosing and timing was clindamycin $(300 \mathrm{mg}, 1 \mathrm{~h}$ before the procedure) and azithromycin $(500 \mathrm{mg}$ immediately before the procedure) (Table 5).

\section{DISCUSSION}

In this study, the current knowledge and awareness regarding antibiotic prophylaxis for the prevention of IE among general
TABLE 5 | Choice of antibiotics in allergic patients for the prevention of IE among the dentists.

\begin{tabular}{lcc}
\hline Antibiotic drug & Frequency & Percentages \\
\hline Azithromycin & 17 & 22.97 \\
$500 \mathrm{mg} 1$ day before & 10 & 58.82 \\
$500 \mathrm{mg}$ 2 $\mathrm{h}$ before & 3 & 17.65 \\
$500 \mathrm{mg}$ 1 h before & 3 & 17.65 \\
$500 \mathrm{mg}$ immediately before & 1 & 5.88 \\
Clindamycin & 41 & 55.40 \\
$300 \mathrm{mg} 1$ day before & 3 & 7.32 \\
$300 \mathrm{mg}$ 2 $\mathrm{h}$ before & 2 & 4.88 \\
$300 \mathrm{mg}$ 1 h before & 1 & 2.44 \\
$300 \mathrm{mg}$ immediately before & 2 & 4.88 \\
$600 \mathrm{mg} 1$ day before & 2 & 4.88 \\
$600 \mathrm{mg}$ 2 $\mathrm{h}$ before & 10 & 24.39 \\
$600 \mathrm{mg}$ 1 h before & 14 & 34.15 \\
$600 \mathrm{mg}$ immediately before & 7 & 17.07 \\
\hline
\end{tabular}

dentists $(n=74)$ in Santo Domingo, Dominican Republic was evaluated using a questionnaire-based survey. The majority of the participants were between 35 and 54 years of age with about half of the study population having 12-22 years of professional experience. At the time of the study, there was no official census of the number of dentists working in the Dominican Republic, hence this cross-sectional survey included data from dentists with a wider age range and experience distribution.

About $78 \%$ of the study population responded that antibiotic prophylaxis was warranted for the prevention of IE. In a study conducted by Al-Fouzan et al., reported that the knowledge level regarding the prevention of IE was around $52.2 \%$ and variations existed between specialists, general dentists, and dental interns (18). A systematic review that included 40 articles was performed by Cummins et al., and it showed that the general knowledge of the guidelines ranged between 1.9 and $100 \%$ and there was a variation between dental students and qualified dentists (19). Although this study was conducted only among general dentists, the knowledge level was within the range mentioned in the previous studies and it may be reasonable to suppose that majority of the dentists in the Dominican Republic had the knowledge about antibiotic guidelines for the prevention of IE.

A study by Boyle et al. reported that $56 \%$ of dental practitioners in Ireland were aware of the guidelines toward antibiotic prophylactic regimen (20). In another study, the dentists' knowledge about antibiotic prophylaxis for the prevention of IE was comparatively low with $<50 \%$ of the dentists showing adequate level (21). In our study, the median knowledge score about antibiotic prophylaxis was 7.0. A study by Kumar et al., conducted among 100 undergraduate dental students from a dental school in India reported that $73 \%$ of the student population were aware of the guidelines toward antibiotic usage for IE prevention (22). The observation was in stark contrast to the findings in this study which reported that the median knowledge scores among dentists acquired through reading 
research articles were higher when compared to classroom teaching. This may be due to differences in undergraduate dental curriculum followed in different countries and this finding warrants attention toward more focused research on this topic.

In this study, the dentists were surveyed about the different cardiac conditions that might warrant antibiotic prophylaxis for the prevention of IE. More than half of the study population responded to prosthetic cardiac valves as a primary indication for antibiotic prophylaxis toward the prevention of IE. Prosthetic valves remain to be one of the major risk factors for the development of IE (23). In a study conducted by Hashemipour et al., among dentists who attended the 47th dental international congress on the prophylactic regimen for prevention of IE, about $95 \%$ of the respondents positively indicated that antibiotic prophylaxis was necessary for patients with prosthetic heart valves (21). The British Society for Antimicrobial Chemotherapy has recommended antibiotic prophylaxis before dental procedures exclusively for patients with a history of previous IE infection or with cardiac valve replacement (24). Another study conducted by Ryalat et al., reported that $87 \%$ of Jordanian dentists recommended antibiotic prophylaxis in patients with prosthetic devices (25). In this study, the vast majority of the study population was aware of the general cardiac indications for antibiotic prophylaxis toward the prevention of IE.

A study conducted by Cloitre et al., reported that $98 \%$ of the respondents recommended antibiotic prophylaxis for tooth extraction and bone tissue surgery, $97 \%$ for soft tissue surgery, and $85 \%$ for endodontic therapy of vital monoradicular teeth (26). Ryalat et al., observed that most dentists felt that dental extractions required prophylaxis (94.5\%), followed by periodontal surgery $(88.2 \%)$, but only $45.7 \%$ thought that endodontic therapy might require prophylaxis. In this study, similar results were obtained with $70.7 \%$ of the respondents recommending prophylaxis for tooth extractions and abscess drainage, $62.2 \%$ for bone grafting procedures, and 56.8\% for periodontal surgery; however, only $32.4 \%$ of dentists recommended prophylaxis for endodontic therapy.

The study conducted by Ryalat et al., observed that amoxicillin was the preferred choice of the antibiotic drug among dentists to prevent IE, followed by clindamycin (17.3\%), and a minority of the dental population preferred metronidazole, lincomycin, gentamycin, or clarithromycin (25). It was also the drug of choice among Nigerian dentist with $89 \%$ preferring it, however, Japanese dentists preferred cephams followed by penicillin drugs $(27,28)$. In this study, amoxicillin remained the preferred antibiotic drug among dentists with $63.5 \%$ warranting its usage for the prevention of IE. In allergic patients, AHA (2008) recommended Cephalexin, Clindamycin, Azithromycin, or Clarithromycin antibiotic prophylaxis for the prevention of IE (2). In this study, more than half of the study population (58.82\%) recommended azithromycin $2 \mathrm{~h}$ prior to the dental procedure. Only three dentists prescribed Azithromycin $500 \mathrm{mg} 1 \mathrm{~h}$ before the procedure, whereas one dentist reported use of $500 \mathrm{mg}$ Azithromycin immediately before the procedure. The standard guidelines recommend a single dose of $500 \mathrm{mg}$ Azithromycin 30-60 min prior to a dental procedure (2). Clindamycin has been recommended as a single dose of $600 \mathrm{mg}, 30-60 \mathrm{~min}$ before a dental procedure, while in this study, 33 dentists were aware of the specific dosage but not about the timing. It is reasonable to suppose that the findings from this study observed that the dentists were not clear about the dosage and timing of the antibiotic prophylaxis to be implemented prior to a dental procedure to prevent IE.

The AHA guidelines state that antibiotic prophylaxis is warranted for high-risk individuals prior to certain dental procedures. The dentists in this study were aware of the indications and dental procedures that warrant prophylactic antibiotic usage, but they were not sure of the timing and dosage of the antibiotics. However, the limitation of this study includes the small sample size, so a generalized conclusion cannot be drawn from the results. This is the first study to assess the knowledge and awareness of antibiotic prophylaxis practices to prevent IE in the dental population in the Dominican Republic. It is to be noted that poor knowledge of the guidelines can result in misuse of antibiotics and antibiotic resistance and this study emphasized the need for continuing dental education, the inclusion of standard guidelines in the undergraduate curriculum, and formal issuance of guidelines from regulatory bodies in the Dominican Republic.

\section{DATA AVAILABILITY STATEMENT}

The raw data supporting the conclusions of this article will be made available by the authors, without undue reservation.

\section{ETHICS STATEMENT}

The studies involving human participants were reviewed and approved by Federico Henriquez y Carvajal University. The patients/participants provided their written informed consent to participate in this study.

\section{AUTHOR CONTRIBUTIONS}

JMA, JAr, and AS designed the study, participated in its coordination, and drafted the manuscript. VB helped draft the manuscript. JAr and JAl participated in data analysis and interpretation. All authors read and approved the final manuscript.

\section{ACKNOWLEDGMENTS}

The authors would like to thank all the dentists who had taken their time to complete the surveys.

\section{SUPPLEMENTARY MATERIAL}

The Supplementary Material for this article can be found online at: https://www.frontiersin.org/articles/10.3389/fpubh. 2020.585332/full\#supplementary-material 


\section{REFERENCES}

1. Jain P, Stevenson T, Sheppard A, Rankin K, Compton SM, Preshing W, et al. Antibiotic prophylaxis for infective endocarditis. J Am Dent Assoc. (2015) 146:743-50. doi: 10.1016/j.adaj.2015.03.021

2. Wilson W, Taubert KA, Gewitz M, Lockhart PB, Baddour LM, Levison M, et al. Prevention of infective endocarditis: guidelines from the American Heart Association: a guideline from the American Heart Association Rheumatic Fever, Endocarditis, and Kawasaki Disease Committee, Council on Cardiovascular Disease in the Young, and the Council on Clinical Cardiology, Council on Cardiovascular Surgery and Anesthesia, and the Quality of Care and Outcomes Research Interdisciplinary Working Group. Circulation. (2008) 116:1736-54. doi: 10.1161/CIRCULATIONAHA.106.183095

3. Goldman L, Ausiello D. Cecil Textbook of Medicine. 22nd ed. Philadelphia, PA: W.B.Saunders Company (2004). p. 956-67.

4. Seymour RA, Lowry R, Whitworth JM, Martin MV. Infective endocarditis, dentistry and antibiotic prophylaxis; time for a rethink? Br Dent J. (2000) 189:610-6. doi: 10.1038/sj.bdj.4800845

5. Ako J, Ikari Y, Hatori M, Hara K, Ouchi Y. Changing spectrum of infective endocarditis. Circ J. (2003) 67:3-7. doi: 10.1253/circj.67.3

6. Canadian Dental Association (CDA). CDA Position on Prevention of Infective Endocarditis. Available online at: http://www.cda-adc.ca/_files/position_ statements/infectiousEndocarditis.pdf

7. Richey R, Wray D, Stokes T. Prophylaxis against infective endocarditis: summary of NICE guidance. BMJ. (2008) 336:7701. doi: 10.1136/bmj.39510.423148.AD

8. Dayer MJ, Jones S, Prendergast B, Baddour LM, Lockhart PB, Thornhill $\mathrm{MH}$. Incidence of infective endocarditis in England, 2000-13: a secular trend, interrupted time-series analysis. Lancet Lond Engl. (2015) 385:121928. doi: 10.1016/S0140-6736(14)62007-9

9. Thornhill MH, Lockhart PB, Prendergast B, Chambers JB, Shanson D. NICE and antibiotic prophylaxis to prevent endocarditis. Br Dent J. (2015) 218:61921. doi: 10.1038/sj.bdj.2015.496

10. Thornhill MH, Dayer M, Lockhart PB, McGurk M, Shanson D, Prendergast $\mathrm{B}$, et al. A change in the NICE guidelines on antibiotic prophylaxis. Br Dent J. (2016) 221:112-4. doi: 10.1038/sj.bdj.2016.554

11. Dayer M, Thornhill M. Is antibiotic prophylaxis to prevent infective endocarditis worthwhile? J Infect Chemother. (2018) 24:18-24. doi: 10.1016/j.jiac.2017.10.006

12. Glenny A-M, Oliver R, Roberts GJ, Hooper L, Worthington HV. Antibiotics for the prophylaxis of bacterial endocarditis in dentistry. Cochrane Database Syst Rev. (2013) CD003813. doi: 10.1002/14651858.CD003813.pub4

13. Cahill TJ, Prendergast BD. Infective endocarditis. Lancet. (2016) 387:88293. doi: 10.1016/S0140-6736(15)00067-7

14. Nishimura RA, Otto CM, Bonow RO, Carabello BA, Erwin JP, Fleisher LA, et al. 2017 AHA/ACC focused update of the 2014 AHA/ACC guideline for the management of patients with valvular heart disease. J Am Coll Cardiol. (2017) 70:252-89. doi: 10.1016/j.jacc.2017.03.011

15. Lockhart PB, Hanson NB, Ristic H, Menezes AR, Baddour L. Acceptance among and impact on dental practitioners and patients of American Heart Association recommendations for antibiotic prophylaxis. $J$ Am Dent Assoc. (2013) 144:1030-5. doi: 10.14219/jada.archive. 2013.0230

16. Elad S, Binenfeld-Alon E, Zadik Y, Aharoni M, Findler M. Survey of acceptance of the 2007 American Heart Association guidelines for the prevention of infective endocarditis: a pilot study. Quintessence Int Berl Ger. (2011) 42:243-51.
17. Zadik Y, Findler M, Livne S, Levin L, Elad S. Dentists' knowledge and implementation of the 2007 American Heart Association guidelines for prevention of infective endocarditis. Oral Surg Oral Med Oral Pathol Oral Radiol Endod. (2008) 106:e16-9. doi: 10.1016/j.tripleo.2008.08.009

18. Al-Fouzan A, Al-Shinaiber R, Al-Baijan R, Al-Balawi M. Antibiotic prophylaxis against infective endocarditis in adult and child patients. Knowledge among dentists in Saudi Arabia. Saudi Med J. (2015) 36:55461. doi: $10.15537 / \mathrm{smj} .2015 .5 .10738$

19. Cummins J, McCarthy M, Esterman A, Karve A, Lee A. Knowledge and compliance of dentists' and dental students' with respect to relevant guidelines for prescribing antibiotic prophylaxis for the prevention of infective endocarditis: a systematic review. J Evid Based Dent Pract. (2020) 20:101311. doi: 10.1016/j.jebdp.2019.01.007

20. Boyle N, Gallagher C, Sleeman D. Antibiotic prophylaxis for bacterial endocarditis-a study of knowledge and application of guidelines among dentists and cardiologists. J Ir Dent Assoc. (2006) 51:232-7.

21. Hashemipour M, Kuraki M. Knowledge of dentists who attended in 47th dental international congress regarding the prophylaxis regimens for prevention of infective endocarditis. J Dent Tehran Univ Med Sci. (2008) 21:210-8.

22. Kumar S, Sneha S. Knowledge and awareness regarding antibiotic prophylaxis for infective endocarditis among undergraduate dental students. Asian J Pharm Clin Res. (2016) 9:154-9. doi: 10.22159/ajpcr.2016.v9s2.13405

23. Nataloni M, Pergolini M, Rescigno G, Mocchegiani R. Prosthetic valve endocarditis. J Cardiovasc Med. (2010) 11:86983. doi: 10.2459/JCM.0b013e328336ec9a

24. Gould FK, Elliott TSJ, Foweraker J, Fulford M, Perry JD, Roberts GJ, et al. Guidelines for the prevention of endocarditis: report of the Working Party of the British Society for Antimicrobial Chemotherapy. J Antimicrob Chemother. (2006) 57:1035-42. doi: 10.1093/jac/dkl121

25. Ryalat S, Hassona Y, Al-Shayyab M, Abo-Ghosh M, Sawair F. Dentists' knowledge and practice regarding prevention of infective endocarditis. Eur J Dent. (2016) 10:480-5. doi: 10.4103/1305-7456.195158

26. Cloitre A, Duval X, Hoen B, Alla F, Lesclous P. A nationwide survey of French dentists' knowledge and implementation of current guidelines for antibiotic prophylaxis of infective endocarditis in patients with predisposing cardiac conditions. Oral Surg Oral Med Oral Pathol Oral Radiol. (2018) 125:295-303. doi: 10.1016/j.oooo.2017.10.002

27. Adeyemo WL, Oderinu OH, Olojede ACO, Ayodele AOS, Fashina AA. Nigerian dentists' knowledge of the current guidelines for preventing infective endocarditis. Commun Dent Health. (2011) 28:178-81. doi: 10.1922/CDH_2718Adeyemo04

28. Nakano K, Ooshima T. Common knowledge regarding prevention of infective endocarditis among general dentists in Japan. J Cardiol. (2011) 57:12330. doi: 10.1016/j.jjcc.2010.09.001

Conflict of Interest: The authors declare that the research was conducted in the absence of any commercial or financial relationships that could be construed as a potential conflict of interest.

Copyright (C) 2020 Aragoneses, Aragoneses, Brugal, Algar and Suarez. This is an open-access article distributed under the terms of the Creative Commons Attribution License (CC BY). The use, distribution or reproduction in other forums is permitted, provided the original author(s) and the copyright owner(s) are credited and that the original publication in this journal is cited, in accordance with accepted academic practice. No use, distribution or reproduction is permitted which does not comply with these terms. 